\title{
Fazendo parentes entre os Baniwa: reflexões sobre as relações em campo ${ }^{1}$
}

\author{
JOÃO JACKSON BEZERRA VIANNA
}

\section{Introdução}

Neste artigo, descreverei as relações possíveis entre os Baniwa e os brancos, considerando o parentesco como abordagem analítica pertinente. Mais especificamente, tratarei da relação estabelecida entre anfitriões indígenas e um antropólogo não indígena. Para tanto, parto da minha experiência etnográfica na qual eu, enquanto hóspede durante o trabalho de campo, fui tratado por Júlio e sua esposa Maria como um filho. Apesar do certo ineditismo desta relação para Júlio, ele contava-me que ela guardava uma analogia com a relação que ele próprio havia estabelecido com os seus patrões não indígenas durante as três décadas em que trabalhou no sistema de aviamento no Brasil, Venezuela e Colômbia. Isso porque Júlio compreendia que os seus patrões, tal como explicitamente formulava para mim, tinham sido como pais para ele. Pretendo demonstrar aqui que estes dois exemplos etnográficos são interessantes, não somente porque a minha relação com Júlio oferece uma continuação das que ele estabeleceu com os seus patrões, mas porque revela também inversões delas. Se Júlio podia ver um pai em seus patrões, no caso que me envolve, ele podia se ver como um pai (e patrão) para mim. Em comum, está o fato de que este vínculo é ambíguo e instável, podendo, em ambos os casos, deslizar de uma relação análoga à consanguinidade para uma relação característica entre afins potenciais (estrangeiros/ inimigos) (cf. Viveiros de Castro, 2002).

Ficará evidente que a filiação (adotiva) é para os Baniwa uma maneira de fazer dos brancos parentes. Porém, dada a dificuldade de obviar (Wagner, 2010, Kelly, 2005) a sua origem exterior, estas relações em especial, mas não exclusivamente, se revelam instáveis e ambíguas. Proponho compreender estas relações baniwa com os brancos enquanto atualizações específicas das relações mais gerais estabelecidas pela afinidade potencial, as quais estou mobilizando por meio do processo do parentesco.

1 Agradeço a leitura atenta de Nicole Soares-Pinto e os comentários de José Kelly que orientou minha tese doutoral, da qual este artigo é um excerto reelaborado. Agradeço ao (à) parecerista anônimo(a) por ter apontando uma questão que me suscitou uma história. Por fim, agradeço ao Júlio e à Maria, para os quais este artigo é uma homenagem. Evidentemente, todos os erros são de minha inteira responsabilidade. 
Portanto, perseguirei os modos como a relação entre os Baniwa e os brancos é atualizada diante do estabelecimento de vínculos efetivos entre eles, quando em uma convivência intensa que envolve coabitação, trabalho conjunto e comensalidade.

Seguindo a abordagem de Wagner (1974; 1977), o parentesco será considerado como o estabelecimento de distinções, fronteiras, cortes contra um fundo de fluxo de relacionalidade generalizada e, para mencionarmos a sua torção amazônica, como um processo de obviação da afinidade. Aproximamo-nos da proposição de Viveiros de Castro (2002) do parentesco enquanto o processo de extração da consanguinidade de um fundo virtual de socialidade (a afinidade potencial). Isso não significa dizer que o parentesco é consanguinidade, mas a sua construção por meio de um processo que pressupõe a afinidade como seu termo não marcado. $O$ parentesco assim entendido não pressupõe uma identificação por meio de laços biológicos coincidentes com a ideia euro-americana de consanguinidade que, como há muito sabemos (Melatti, 1976; Seeger, 1981) e cujas consequências ainda estamos compreendendo (Soares-Pinto, 2018), não caracterizam o parentesco ameríndio. Considerando isso, acompanharemos uma demonstração do esforço baniwa de fazer dos brancos (alguns deles) seus parentes, notando o modo como os Baniwa buscam extrair (alguma) consanguinidade destes afins potenciais. $\mathrm{O}$ parentesco será a abordagem teórica para estas relações supralocais e supra regionais (ou interétnicas) que já foram denominadas na literatura antropológica como sendo "pseudo-parentesco", "parentesco fictício", "parentesco precário" ou "parentesco complementar".

A propósito das relações indígenas com os não indígenas, a literatura etnológica destaca a figura dos patrões dos sistemas extrativistas-mercantis (Ramos et al 1980; Gow 1991; S. Hugh-Jones 1992; Bonilla 2005; Wright 2005; Andrello 2006; Coutinho 2007; Killick 2008; Walker 2013; Costa 2016, entre outros). Tais descrições se apoiam em diferentes abordagens, sendo possível destacar uma série de noções mobilizadas para compreender estas relações na Amazônia: assimetria, simetria, sujeição, parasitismo, filiação adotiva, maestria, predação, simbiose, hierarquia e relacionalidade complementar. As análises destes estudos se valem de abordagens que consideram a história, a cosmologia, a mitologia, a economia e o parentesco.

No que tange ao parentesco, a relação entre indígenas e não indígenas são compreendidas por duas principais formulações: 1) compadrio ou outras relações de parentesco ritual e; 2) filiação adotiva. Em termos gerais, sob o compadrio e o parentesco ritual podemos localizar uma série de etnografias que dedicaram descrições de fôlego sobre as relações entre empregados indígenas e patrões não indígenas; por sua vez, orbitando em torno dos termos da filiação adotiva, podemos encontrar, além das relações indígenas com os patrões, descrições de antropólogos não indígenas com os seus anfitriões, embora costumem ser breves e alusivas. Não é incomum à literatura, por um lado, considerar estas relações de parentesco ritual com os brancos como sendo de um parentesco fictício ou falso, em que "o patrão não é verdadeiramente um parente" e, por outro lado, em relação à filiação adotiva, considerar as relações de parentesco com os brancos variando entre a "ficção complacente" (Albert 2015) e a parcialidade ou incompletude (Fausto 2008). Neste artigo, desconfio destas duas apreensões como modo de descrever as minhas relações com Júlio Cardoso e Maria. 


\section{Chegando}

Às margens do rio Aiari², afluente do rio Içana, vivem 1063 pessoas (SESAI/2013) em 19 comunidades e sítios, cujo percurso por rio da sua primeira comunidade à última é de aproximadamente $141 \mathrm{~km}$. Todas essas comunidades são baniwa porque são fundadas e habitadas predominantemente por pessoas baniwa, com uma única exceção, a comunidade Jurupari, a mais à montante, fundada e habitada pelos Kubeo, um povo de língua tukano. As comunidades baniwa podem ser caracterizadas por suas relações agnáticas, sob o signo de um único clä $\tilde{a}^{3}$ patrilinear. Apesar disso, considerando a exogamia frátrica característica dos Baniwa e seu padrão residencial virilocal, as comunidades frequentemente compõem-se também de homens de outros clãs, em geral, um cunhado, irmão da esposa, ou um genro, caracterizando um padrão de uxorilocalidade temporária. Estes afins estão sempre em menor número em relação à parentela agnática fundadora, os "donos da comunidade", idzakale iminali. A média populacional dos grupos locais (as comunidades e sítios) ${ }^{4}$ do Aiari, de acordo com o censo da SESAI de 2013, é de 55,9 habitantes e 9,7 grupos domésticos ${ }^{5}$, variando entre os menores sítios, com 7 pessoas, e as maiores comunidades com um pouco mais de 130 habitantes.

Ao chegar pela primeira vez na comunidade baniwa de Santa Isabel (Awiñapamiana), uma entre as dezenove situadas às margens do rio Aiari, eu fui recebido por Júlio Cardoso (83 anos) e por sua esposa Maria Silva (75 anos), que moravam sozinhos em sua casa. Júlio é considerado o fundador dessa comunidade e seu chefe. Eu já tinha me hospedado em outras comunidades baniwa, mas até então não tinha me sentido acolhido nestas como em Santa Isabel. Conversando sobre isso, Júlio explicou-me que isso ocorreu porque os seus parentes baniwa do rio Aiari não estavam "acostumados" com os brancos, eles tinham medo, os estranhavam, tinham vergonha. Diferentemente, ele, por ter sido "criado no meio dos brancos, na mesma casa que eles, como se fosse filho deles", não experimentava a mesma sensação e, por isso, sabia lidar comigo. A minha chegada causou alguma sensação inicial. Os parentes das comunidades mais próximas procuravam Júlio e Maria, questionavam-lhes se não tinham medo e/ou vergonha de mim, mas Júlio argumentava que já tinha tido longas relações efetivas com os patrões não indígenas do sistema mercantil-extrativista durante três décadas entre Brasil, Venezuela e Colômbia.

2 O território baniwa é extenso, compreende o rio Guaínia entre Colômbia e Venezuela, e, no Brasil, o curso alto do rio Negro, todo o rio Içana e seus afluentes - Cubate, Cuiari, Quiari e Aiari. A população baniwa é de 17.646 indivíduos (SESAI 2014; 2000; XIV Censo Nacional de Poblacion y Viviendas 2011) que se distribuem, somente no Brasil, em 93 comunidades. Os Baniwa compõem o que se designou como sistema regional do Rio Negro, que relaciona mais de 22 povos indígenas, representantes das famílias linguísticas Tukano Oriental, Aruak e Maku, situados no Noroeste Amazônico.

3 Classicamente na literatura rionegrina, clã é considerado um grupo de descendência patrilinear baseado nas relações de parentesco agnático, cujos membros compartilham emblemas rituais comum e, no caso baniwa, uma mesma origem mítica na cachoeira de Hipana e um epônimo animal que emerge nesta ocasião como um ancestral. É importante sublinhar que a ideia em torno da agnação está dada em um plano mítico e não genealógico, o que é de fundamental entendimento, pois elimina de saída a ideia de que se poderia traçar a partir da genealogia uma "origem" das linhagens clânicas baniwa, mobilizadas por meio de substâncias herdadas biologicamente ou prerrogativas legadas juridicamente.

4 Estou entendendo grupo local como sendo uma comunidade que reúne diferentes grupos domésticos ou sítio constituído por um único grupo doméstico, que é designado por um topônimo em baniwa.

5 Por grupos domésticos, estou designando famílias extensas sob a chefia de um homem casado com filhos que pode incluir seus netos, filhos de suas filhas não casadas, sua mãe viúva, e mesmo, um irmão solteiro ou viúvo. Eles são abrigados em uma única estrutura doméstica que compreende uma casa e uma cozinha que se estende a um conjunto de roças. Nas malocas tradicionais, não mais utilizadas pelos Baniwa como habitação comunal, um grupo doméstico era uma família que se alocava em um dos seus compartimentos domésticos. 
Ele fazia notar sua experiência por falar fluentemente, além do baniwa (sua primeira língua), o português, o espanhol e o nheengatu, além de se orgulhar de possuir uma casa "bonita", feita de tábuas de madeira serradas e pintadas, cobertas com telhas laminadas de alumínio, ao invés das de taipa, cobertas por palhas. Sua experiência se evidenciava também porque, dono de uma aposentadoria, "emprega" seus parentes em esporádicos serviços que ele, já velho, não consegue mais fazer, como abrir uma roça nova. Todos esses elementos distinguem Júlio dos seus parentes co-residentes.

A espaçosa e subdivida ${ }^{6}$ casa de Júlio e Maria muitas vezes estava vazia. Os seus seis filhos estavam quase todos casados, alguns morando em Santa Isabel, mas também em outras comunidades, a exemplo de Dzoodzo e Ademar. Júlio é um entusiasta da educação formal indígena e preparou os seus filhos para a escolarização, porém o seu êxito nesta empreitada teve como efeito o fato de que seus filhos ficaram divididos entre diferentes comunidades, a de seu pai e aquelas onde lecionam. Assim, a convivência com os filhos é provavelmente menor do que Júlio e Maria desejariam. Diante desse contexto, passei a participar das atividades do casal Júlio e Maria e, por meio deles, das atividades que envolviam a comunidade, tal como as idas diárias aos centros comunitários para as refeições matutinas e vespertinas, que ocorrem sempre coletivamente ${ }^{7}$, e para os trabalhos comunitários. De modo pragmático, a ausência de um filho na casa deles era sentida na lida da roça, no trabalho comunitário ${ }^{8}$ e enquanto companhia. Retrospectivamente, percebo que tentei ocupar essa lacuna e em contraste com as minhas outras experiências em trabalho de campo, esta configuração me fez sentir com um lugar na comunidade e na família de Júlio. Ao mesmo tempo, eu tinha a sensação de que Júlio e Maria encontravam um modo mais ou menos apropriado para lidar com a estranha situação de ter um branco com eles. Por mais acostumado que Júlio alegasse estar em viver com os brancos, tinha algo de inédito nessa convivência.

\section{Filiação adotiva e os antropólogos}

Tentemos imaginar a bizarra situação em que Júlio e Maria se encontravam. Desde a minha chegada a Santa Isabel, eles passaram a viver sob um mesmo teto, comendo e trabalhando junto com um estrangeiro branco. Para as comunidades baniwa do rio Aiari, não é absolutamente estranho ter entre eles brancos, pois, mesmo que seja possível que se passem semanas ou meses sem a visita de não indígenas em suas comunidades, é relativamente regular a visita e presença de assessores de ONGs, enfermeiros dos serviços de saúde, militares de exército, missionários religiosos. Antes da demarcação da Terra Indígena, recebiam ainda visitas de patrões do extrativismo-mercantil e notavam movimentações de narcotraficantes, guerrilheiros e garimpeiros. Ocorre que, em geral, a presença dos estrangeiros, além de limitada temporalmente é marcada por uma separação e autonomia. Os brancos chegam às comunidades com seus

\footnotetext{
6 A casa possuía quatro quartos: 1, o do casal; 2, o de Dzoodzo, para os finais de semana; 3, o de Ademar; 4, o de hóspedes, cuja janela está virada para o pátio da comunidade. A maior parte das casas baniwa, mesmo que de tábua serrada, não têm divisórias com paredes, os distintos ambientes são notados pelo uso e pela ocupação de seus moradores.

7 As refeições coletivas imprimem um aspecto muito marcante no cotidiano das comunidades baniwa. Para uma descrição das refeições comunitárias baniwa (e koripako), ver Journet (1995) e Vianna (2017).

8 As atividades comunitárias são realizadas semanalmente, das quais é comum que os velhos, mas também os doentes, já sem o vigor de outrora, deixem de participar. Para evitar fofocas que os acusem de "preguiça", os ausentes podem enviar parentes descendentes para que a ausência seja atenuada.
} 
próprios barcos de alumínio e motores de popa, guiados por pilotos indígenas contratados, ficam em casas separadas, levam sua própria comida e têm atividades e demandas muito específicas para os seus dias na Terra Indígena. Diferentemente, eu dependia das caronas dos próprios baniwa, não vivia em uma casa separada, não tinha ninguém que eu empregasse e minhas demandas não eram evidentes.

Eu não tinha a mesma autonomia que os outros brancos e, menos ainda, a mesma autonomia que os Baniwa: eu não tinha roça, minha esposa não me acompanhava e, tampouco, podia condicionar minha subsistência à minha capacidade de pescar e caçar. Eu era de certa maneira um homem não adulto, porque

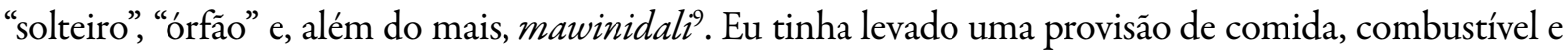
dinheiro para realizar trocas, mas ainda assim era evidente minha dependência em relação à comunidade e, em especial, aos meus anfitriões. Eu dependia de Júlio e Maria como um filho depende de seus pais, e eles sabiam disso. A situação era muito artificial, não porque falsa, mas porque atípica, exigente de acomodações que precisavam ser deliberadamente formuladas para que a convivência entre nós se realizasse de uma maneira aceitável. Eu era um estrangeiro, mas diferentemente dos outros brancos (ialanawi) da região, eu me posicionava como um "filho", o que me tornava, por um lado, ainda mais estranho, mas, por outro, uma novidade curiosa que podia ser assimilada nas relações já previstas pelo parentesco baniwa, o que inclui as relações com os patrões ${ }^{10}$. Não entendo completamente o porquê deles aceitarem essa relação, porém tenho a impressão de que Júlio esperava que eu contribuísse com o seu filho Dzoodzo na formulação de projetos para os Baniwa. Mais especificamente, Júlio pretendia que a comunidade de Santa Isabel, até então fora do "circuito indigenista", beneficiasse-se de projetos" ${ }^{11}$.

A respeito destas parcerias com os brancos, Dzoodzo, após ler alguns dos relatos de Koch-Grunberg no rio Aiari em 1903 (2005), destacou para mim uma passagem na qual o etnógrafo alemão descrevia sua amizade com Mandu, chefe walipere da maloca Cururu-Cuára, hoje comunidade Canadá, vizinha à Santa Isabel. Nesse trecho, Mandu pedia para que Koch-Grunberg entregasse um recado diretamente ao governador do estado quando o encontrasse: que enviassem um representante até eles. Dzoodzo, então, comentou que, pelo menos desde essa época, os Baniwa estão cobrando seus direitos e tentando realizar parcerias, há muito demonstrando a sua política para as relações diplomáticas.

No post scriptum do livro A queda do céu de Kopenawa e Albert, este formula as parcerias entre antropólogos não indígenas e anfitriões indígenas como sendo um "pacto etnográfico", estabelecido implícita ou explicitamente entre eles. Sobre isso, o autor comenta:

Ao lhe oferecerem seu saber, os anfitriões do etnógrafo aceitam a incumbência de ressocializá-los numa forma que lhes parece mais adequada à condição humana. Contudo, para além da cumplicidade ou empatia que o estranho noviço possa ter inspirado, a transmissão visa antes de tudo, para além de sua pessoa, o mundo do qual ele jamais deixa de ser um representante, queira ele ou não. De fato, seus esforços pedagógicos, seus anfitriões têm por objetivo primeiro tentar reverter, tanto quanto possível, a troca desigual subjacente à relação etnográfica. De modo que os ensinamentos de nossos supostos "informantes" são dispensados por razões de ordem principalmente diplomáti-

90 mesmo que panema, termo que designa azar na caça e pesca.

10 Para uma descrição das relações de parentesco entre os Baniwa e os patrões brancos do extrativismo mercantil, ver Vianna (2017).

11 Hoje a situação mudou e a comunidade tem recebido uma série de projetos, o que não é tributário à minha estadia e influência, mas à atuação política e empreendedora de Dzoodzo junto a instituições parceiras como o Instituo Socioambiental (ISA) 
ca. Sua paciente educação se aplica, em primeiro lugar, a nos fazer passar da posição de embaixador improvisado de um universo ameaçador ao papel de tradutor benevolente, capaz de fazer ouvir nele sua alteridade e eventualmente possibilitar alianças (Albert, 2015: 521).

O pacto etnográfico de Albert ajuda a elucidar alguns dos pontos da minha experiência em campo, mas não todos. Por isso, pretendo apontar relações que extrapolam os termos propostos pelo autor. Os Baniwa possuem atualmente diferentes associações que estão vinculadas à Federação das Organizações Indígenas do Rio Negro (FOIRN), cuja atuação é muito importante na região. Eles estão articulados com o movimento indígena local, regional e nacional, com infiltrações na política administrativa municipal, cuja melhor expressão foi o mandato de André Fernando Baniwa na vice prefeitura de São Gabriel da Cachoeira (AM). É possível dizer que os Baniwa têm, nas últimas décadas, formado os seus próprios “embaixadores”, enviando-os para São Gabriel da Cachoeira, Manaus e Brasília. Como apontou Albert (2014: 129) em outro artigo, os povos indígenas "estão se tornando cada vez mais sujeitos de sua própria história e leitores de seus próprios etnógrafos”. Mas isso não significa, entre os Baniwa ao menos, que dispensem por completo os seus "tradutores benevolentes" estrangeiros.

A aliança que eu estabeleci no início do trabalho de campo com os Baniwa - a qual perdura até hoje - tinha como base as cooperações com o movimento indígena. Ocorre que em relação aos meus anfitriões, durante a minha estadia, eu notava que havia concomitantemente uma série de acordos cotidianos de outra ordem. O pacto que se estabelecia, entre o implícito e o explícito, com os meus anfitriões Júlio e Maria implicava uma assimetria (provimento deles e dependência minha). Nesse âmbito, minha contribuição não era capaz de simetrizar a relação entre nós no cotidiano comunitário e, por isso, a assimetria se alinhavou a uma já existente entre os Baniwa: a filiação em sua modulação adotiva. Essa foi a solução desenvolvida para a situação que nos defrontava, mas não é uma regra.

As circunstâncias em que vivem atualmente o casal Júlio e Maria favoreceram o modo como esta relação foi estabelecida, mas posso supor que outras relações seriam possíveis também. Quando em visita ao campo da minha esposa na Terra Indígena rio Guaporé ( $\mathrm{RO}$ ) eu fui prontamente designado de cunhado por um homem Wajuru que a considerava sua irmã, fazendo-me trabalhar com ele na roça de seus parentes em troca de bebida fermentada. Killick (2008) descreve que a relação com seu principal anfitrião indígena podia ser expressa pela parceria comercial-ritual nos termos dos próprios Ashéninka como sendo ayompari. Nesse último sentido, posso formular ainda minha relação com Dzoodzo, o filho de Júlio, como sendo de amizade ${ }^{12}$ (ou camaradagem ${ }^{13}$ ) e não de germanidade.

12 Para somente alguns exemplos da articulação entre relações de amizade e parentesco nas Terras Baixas da América do Sul, ver Killick (2008), Santos-Granero (2007), Soares-Pinto (2014), Vianna (2017) e Matos (2018). Para esses autores, com exceção dos dois primeiros, essas formas de amizade possuem uma consideração importante com a distância e a afinidade potencial.

13 A camaradagem baniwa é uma relação de amizade ritual formalizada entre parentes distantes (co-afins e afins potenciais). A camaradagem de sexo cruzado é tipicamente estabelecida pelos rituais de iniciação. No caso da iniciação masculina, os meninos-iniciandos presenteiam uma mulher com cestos e outros utensílios que manufaturaram durante a reclusão que antecede o ritual, e elas retribuem pintando-lhes antes do ato final da iniciação, o benzimento kalidzamai. No caso feminino, um homem, ou então uma mulher, é escolhido pelos pais da moça que menstruou pela primeira vez para cortar o seu cabelo. A camaradagem de mesmo sexo entre homens não é algo que está enunciado na iniciação ritual, como é possível para as mulheres, ocorrendo entre parceiros e aliados potenciais, mas que não são propriamente parentes. A relação é inaugurada mediante o convite de um dos camaradas ao outro, o qual não pode recusar. Esses momentos rituais inauguram uma prática de trocas regulares de peixes, caças, frutas, presentes da cidade, mas principalmente respeito. $\mathrm{O}$ "respeito" tem uma forte conotação de evitar conflitos, fofocas e divergências, exaltando uma relação que obvia as diferenças entre estes amigos, ampliando as redes de parentesco. 
É evidente que eu sabia que Júlio e Maria não eram os meus pais, tanto quanto eles sabiam que eu não era filho deles. No lugar, eu poderia dizer que no período em que convivemos na comunidade de Santa Isabel, eles eram "como se" fossem os meus pais e eu "como se" fosse o filho deles. Mas é preciso alertar que com o "como se" não quero apontar uma falsidade ou parcialidade das relações de parentesco estabelecidas, mas, sobretudo, marcar que estes posicionamentos foram deliberadamente induzidos, permitindo uma convivência que se mostrou provisória, ainda que virtualmente pudesse não ser. Vemos assim o caráter analógico do parentesco que não é, por isso, um processo distinto do parentesco baniwa, somente porque envolve um estrangeiro. Afinal, quais relações de parentesco não procedem construindo, favorecendo e pressionando posicionamentos e atitudes que se esperam das pessoas que ocupam determinadas posições em uma rede de relações?

É preciso apontar que nunca chamei os meus anfitriões pelos termos de pai e mãe, do mesmo modo que eles nunca se referiram a mim pelos termos de filho e, tampouco, eu desdobrei da relação de filiação adotiva a classificação e as atitudes dos filhos de Júlio e Maria como sendo irmãos. Isso revela, em parte, a esquisita situação etnográfica em questão, a adoção de um branco, mas, em parte também, a própria filiação adotiva baniwa. Talvez por isso vejo-me em uma relação distinta daquelas descritas em muitas etnografias em que os próprios termos da filiação são o modo pelo qual os antropólogos enunciam a suas relações com seus anfitriões indígenas. É diante dessas ressalvas que podemos prosseguir nessa descrição. Sobre isso, parece-me útil o comentário incrédulo de Albert sobre as adoções dos antropólogos:

As breves e convencionais considerações acerca da "adoção" do antropólogo que povoam a literatura etnográfica sempre me pareceram da ordem da ficção complacente. O que pode afinal significar "ser adotado" por seus anfitriões quando estes se veem cada vez mais submetidos à investida de um mundo inquietante e nefasto, do qual o antropólogo é, para eles, de algum modo um emissário, por mais grotesco ou inofensivo que possa parecer à primeira vista? Logo ficou evidente para mim que os Yanomami só tinham aceitado minha incômoda e esquisita presença por precaução, como teriam feito, pelas mesmas razões, com qualquer outro visitante estrangeiro, nape ("forasteiro", "inimigo"), pelos menos enquanto este não demonstrasse intenções abertamente hostis (Albert, 2015: 520).

Não concordo com o caráter fictício atribuído à adoção por Albert, ainda que eu note, como o autor, certa complacência nas descrições dessas relações, quase sempre muito breves. $O$ fato de um antropólogo ser branco, forasteiro e potencialmente inimigo não significa que ele não possa ser pensando potencialmente como um parente. Os sistemas de parentesco na Amazônia oferecem diferentes possibilidades para um estrangeiro (afim potencial) ser incluído no campo dos parentes (Viveiros de Castro, 2002), o que nos permite abdicar da noção de um parentesco falso (ou fictício) para abordar relações com os não indígenas. Porém, é importante ressaltar que, conforme o alerta de Albert, os brancos são potencialmente inimigos, mesmo aqueles que foram adotados. Sobre isso, alguns dos meus interlocutores baniwa dizem que os patrões que eram "como um pai" podiam se revelar inesperadamente, quando contrariados, inimigos. 
É verdade que, pelo processo do parentesco, tal como tenho descrito, a relação de adoção de um antropólogo implica obviar a sua parte-afim, o mesmo processo que ocorre no caso dos patrões. Porém, nada tem de contraditório nisso, na medida em que a definição de obviação (Wagner 2010) aponta justamente para o fato de que o mascaramento desta parte-afim não é a sua aniquilação ou extinção, mas uma eventual invisibilização por meio de uma dinâmica figura-fundo. Assim, dizer que antropólogos não indígenas e anfitriões indígenas podem ser parentes não significa uma relação de confiança mútua incondicional entre eles. Em suma, inimigos e parentes podem estar separados por uma linha muito tênue e móvel, motivo pelo qual não há uma impossibilidade formal de inimigos se tornarem parentes, como tampouco de parentes se tornarem inimigos.

\section{Entre a ficção e a complacência}

Em um primeiro momento, Júlio e Maria diziam-me que os seus parentes da comunidade não entendiam o que eu fazia entre eles e porque eu os ajudava. Eles queriam saber o que eu ganhava de Júlio em troca do trabalho na roça, afinal, à exceção de um filho, ninguém trabalharia "de graça”. Júlio chegou a me dizer que não teria como me pagar e que, portanto, eu não deveria trabalhar. As pessoas de Santa Isabel diziam que nunca tinham visto um branco trabalhando desta maneira na comunidade deles, mas, com o tempo, quando mais acostumados à cena, passaram a perguntar por mim utilizando os termos relacionados à filiação que notavam entre mim e meus anfitrióes. Todavia, como já apontei, Júlio e Maria nunca utilizaram estes termos comigo, mas me informavam que eu era referido desta maneira na comunidade.

Nos primeiros dias na casa de Júlio, ele se sentava comigo para me contar histórias, perguntando o que eu queria saber, mas eu não lhe apresentava muitas demandas objetivas relacionadas ao que ele imaginava ser a minha pesquisa. Estranhamente, para ele, eu insistia em acompanhá-lo em suas atividades diárias e ele resistia de diferentes maneiras. Júlio foi cedendo até eu me sentir relativamente integrado às atividades de sua casa e da comunidade. Nossa relação estava em uma aberta negociação, ele me oferecia o lugar de branco-estrangeiro e eu reivindicava a posição de filho. Certo dia, estávamos em cima do caibro da nova cozinha em construção, amarrando folha de caranã que serviria como cobertura. Nesta ocasião, Júlio me disse que eu não deveria trabalhar com ele desta maneira, pois, se assim fizesse, eu seria como filho dele e, então, quando eu fosse embora, ele ficaria na comunidade lembrando de mim. Vejamos que eu não era filho porque comia e bebia com eles, a propósito da comensalidade, mas principalmente porque "trabalhava" com os meus anfitriões: Júlio, Maria e a comunidade de Santa Isabel. De algum modo, o idioma das substâncias qua substância parece menos importante aqui do que em outros contextos etnográficos para expressar uma familiarização em curso.

As marcações que caracterizam esta relação ("como", "como se", "tipo") não é, como já mencionei, tanto para apontar parcialidade ou falsidade, mas mais notadamente para assinalar sua duração. Júlio previa, justamente, que eu seria como um filho, mas que depois partiria de volta para a minha esposa e os meus pais, meus parentes primeiros, desmascarando a relação estabelecida entre nós. Algo análogo lhe ocorreu quando viveu por um tempo entre os Piaroa, que pretendiam familiarizá-lo via 
aliança matrimonial. Júlio recusou, explicando que sua esposa e filhos o aguardavam, mas que voltaria um dia para agradecer, o que me contava de maneira didática, cobrando um agradecimento análogo: eu não poderia não voltar.

Em Santa Isabel, sempre ocorriam festas em que se utiliza caxiri ${ }^{14}$. Nelas as pessoas podem ficar bêbadas e, então, dançam e entretém conversas mais alongadas e íntimas. Nestas ocasiões, dois camaradas podem conversar entre eles, bem como dois cunhados ou duas concunhadas, além de alguns flertes que podem acontecer entre os jovens. Nessas circunstâncias, é comum que as pessoas cantem os kamarataka, um gênero de músicas semi-improvisadas, motivadas pela embriaguez, em que as mulheres cantam umas para outras, para seus filhos, suas concunhadas e maridos. O tom pode ser jocoso e descontraído, com a finalidade de divertir um público, mas, quando realizados de modo mais reservado, assume um tom melancólico e queixoso. Assim, em um determinado momento da referida festa, sentei-me com Júlio e Maria e esta, então, disse para mim que sentiria saudade quando eu fosse embora e cantou em baniwa:

Nunca vi pessoa branca chegar perto assim de mim. Será que ele vai estar sempre com a gente? Eu não queria que ele, menino, saísse já de mim, porque é o único que me dá bom dia. Primeira vez que vi pessoa assim, chegando na minha casa, eu sou índia, e ele está visitando bem legal como se fosse meu filho. Será que ele vai agradecer ou não vai voltar? Não existe meu filho parecido como você, branco. Não sei se ele sente que eu trato bem ele. Será que ele vai voltar para agradecer, ou ele veio só enganar, e nunca mais para voltar com a gente de novo (Tradução livre).

$\mathrm{Na}$ música, notamos que Maria expressa sua reflexão sobre o fato estranho e curioso de ter um filho como eu, branco, cujos hábitos lhe parecem particulares, mas aponta também o caráter provisório da filiação que se estabelecia, bem como a suspeição que eu inspirava em meus anfitriões. Eu era "como" um filho, mas será que eu voltaria, será que eu agradeceria? Eu não era um filho falso, mas um filho branco-estrangeiro, provisório e, por isso, um filho suspeito e potencialmente inimigo, mas ainda assim um filho. Vale assinalar que se a suspeição e a provisoriedade da filiação são bastante evidentes no caso que me envolve, isso não significa que elas sejam marcas exclusivas às relações com os "filhos brancos", podendo ser também atualizadas por filhos legítimos, sobre isso veremos adiante.

Em um relato de Firth no estudo clássico Nós, os Tikopia, o autor registra sua desconfiança, não em relação aos antropólogos, mas aos escritores europeus que visitavam a África à época no afã de descrever e se relacionar com tribos daquele continente:

Como a maioria dos antropólogos, encaro com ceticismo a alegação de qualquer escritor europeu de que "foi aceito pelos nativos como um deles". Deixando de lado a questão da presunção, essa alegação se baseia geralmente numa avaliação equivocada da polidez nativa ou de uma momentânea identificação verbal emocional como eles mesmos de uma pessoa que compartilha suas simpatias. A mim mesmo, inúmeras vezes me asseguraram que era "igualzinho a um tikopia”, porque obedeci em algumas particularidades aos hábitos econômicos e sociais de seu povo, como danças com eles e observar a etiqueta de (pseudo) parentesco, ou porque, esposei seu ponto de vista em algum

14 Bebida fermentada de mandioca, pupunha, abacaxi e outras frutas. 
problema de contato com a civilização. Mas encarei isso como um cumprimento, da mesma ordem que uma referência a "nossa" canoa ou "nosso" pomar ("seu e meu") por um de meus irmãos de cortesia, o que significava certos privilégios concretos, mas não uma participação real na propriedade. (Firth 1998: 95-6).

A discussão que Firth precipita envereda por outros caminhos, a este pretexto [...] pretendo realizar uma distinção importante [...], a saber, ser adotado por um anfitrião indígena não é o mesmo que "virar nativo". A minha adoção por Júlio e Maria parte do pressuposto da diferença entre nós. Eu sou um filho, mas um filho branco, a partir de quem eles obtém alguns objetos (presentes), conhecimentos (histórias de outro lugar, administração de remédios etc.) e habilidades diferentes (elaboração de projetos, organização de livro, revisão de textos) das que eles podem encontrar, por exemplo, no território em que vivem e/ou de seus outros filhos e parentes. A filiação adotiva não está apoiada na "pura identidade", ao contrário, ela extrai proveitos justamente da diferença, do mesmo modo que precisa tomar cuidado com ela.

A adoção do antropólogo por parte dos seus anfitriões indígenas é um ato de invenção, deliberadamente construída tal como, no limite, são todas as relações de parentesco. Mas reconhecer tal construção não deve necessariamente significar compreendê-la como sendo falsa e complacente. Essa relação que, assim descrita, revela-se artificial, porque reveladora dos artifícios que a favorecerem, não implica um processo de conversão metafísica ou cultural que culmina na identidade "virar nativo", ao contrário, pressupõe as diferenças que podem ser relacionadas.

\section{Reposicionamentos}

Após o retorno para a minha segunda estadia em Santa Isabel, percebia que meus anfitrióes me viam com menos suspeição. Júlio se queixou de maneira afetuosa da minha partida em minha última estadia, dizendo-me que passou um tempo pensando em mim, lembrando de mim "como que apaixonado". Expressão utilizada por ele para falar de uma lembrança persistente que produz um tipo de tristeza. Maria dizia, enquanto estávamos na roça, que toda vez que ouvia o zunido do motor dos aviões e via o seu rastro de fumaça no céu me imaginava voando. Contavam-me, além disso, que conversavam sobre como seria quando eu fosse definitivamente embora, imaginando como se sentiriam.

Eu notava a satisfação com a minha volta, o que se não tivesse acontecido teria sido compreendido como ingratidão da minha parte, tal como Maria cantou para mim. Porém, tinha a impressão também, no decorrer dos dias desta minha nova estadia, que pairava sobre eles um certo desconforto com o caráter provisório que eu impunha à relação. Era eu quem chegava na casa deles, do mesmo modo que era eu também quem partia da casa deles. Em nenhuma de minhas três estadias permaneci mais que três meses na casa de Júlio e Maria, pois percebia que eu poderia estar me alongando. Notava que os arranjos estabelecidos em torno da nossa relação, a qual tenho caracterizado pela filiação adotiva, reabriam-se. Em algum momento, passei a perceber que eu estava deixando de ser um filho cooperativo, para ser um hóspede potencialmente impertinente, talvez algo como um filho maapatsika (bastardo) que procura o pai. A relação com os meus anfitriões não pode ser descrita por meio de posições fixas. 
Em parte, suspeito, a inconveniência da minha presença que me reposicionou enquanto um hóspede, quando minha estrangeiridade ganhou um primeiro plano, teve relação com fofocas que correram o rio Aiari e no rio Içana no intervalo entre as minhas estadias em Santa Isabel. Circulavam boatos que uma pesquisadora em uma comunidade do rio Içana pagava com dinheiro os seus anfitriões, a partir do que os cunhados de Júlio cobraram explicações. Então, com a minha chegada para esta segunda estadia, Júlio se esforçou para esclarecer a situação para os seus parentes co-residentes, reforçando durante umas das refeições coletivas realizadas no centro comunitário que eu era apenas um estudante e não como os outros brancos que têm dinheiro de projetos (assessores de Ongs) ou de comércio (patrões) ou do governo (políticos).

Essa conversa, aparentemente e provisoriamente, aplacou algumas das desconfianças. No entanto, não demorou para que tivéssemos notícias de que uma onça estivesse rondando a comunidade. Júlio contou-me que nunca tinha visto uma onça rondando a comunidade de maneira tão próxima e por tantos dias, motivo pelo qual presumia que aquela não era uma onça qualquer, mas uma onça-pajé. A desconfiança de Júlio era de feitiçaria encomendada por alguém com inveja dele, isso porque ele tinha "um branco" que "passava bem" em sua casa. A onça tinha matado Sula, uma cachorra filhote de estimação de Maria e mesmo após isso, continuava nas redondezas. Nós víamos os seus rastros nas trilhas para a roça, os caçadores da comunidade também traziam outras notícias e marcas de sua presença. Consecutivamente, apareceram também cobras em torno da casa de Júlio, algo que definitivamente não era ordinário. Enfim, avizinhava-se da comunidade e, em especial, da casa de Júlio, uma sombra suspeita. Eu sentia uma certa tensão no ar, não somente pela relativa preocupação que todos experimentavam, mas porque eu poderia ser de alguma maneira o objeto do empreendimento xamânico. Mas os dias passaram, a onça foi embora e a tensão diminuiu, e eu sentia novamente que minha presença parecia menos impertinente, reconquistando minha posição anterior.

\section{A filha renegada}

$\mathrm{O}$ ataque da referida onça à Sula nos traz questões adicionais. Maria tinha grande apreço por Sula, pois ela, entusiasmadamente, diferente dos seus irmãos, os cachorros Pica Pau e Cabeçudo, lhe fazia companhia nas idas à roça. $\mathrm{O}$ ataque da onça ocorreu justamente em um destes percursos. Maria estava voltando da roça e, como sempre, em seu encalço, vinha Sula que entrava no mato, saindo da trilha, para somente reaparecer adiante, retomando o caminho e a companhia de sua dona até o rumo de casa. No fatídico dia, Sula demorou para ressurgir, deixando Júlio e Maria preocupados, o que os forçou a voltarem para resgatá-la, mas foi em vão, a encontraram já morta à beira da trilha, despedaçada. Pude saber que este ataque poderia ter sido evitado, pois no dia anterior Maria sonhou não somente com um prenúncio do que aconteceria porvir, mas com o próprio evento.

No sonho, Maria estava na varanda em uma casa na cidade quando chegou de carro Baixinho, um então vereador baniwa de uma comunidade do rio Içana. Carro estacionado, ele desceu e se dirigiu à Maria, pedindo a sua filha em casamento. Maria observou que ao seu lado havia uma menina bonita, mas sem hesitar disse: "Ela não é minha filha”. Explicou, então, para Baixinho que aquela menina não 
era sua filha, pois a tinha pegado na comunidade Koitsiali e que, se quisesse, ele poderia levá-la, ela não se importaria. Baixinho, então, tomou Sula (em forma antropomorfa) pelas mãos e com o mesmo carro que chegou foi embora.

Esta é a face onírica do que ocorreu na trilha para a roça envolvendo Sula e a onça e, por este motivo, poderia ter sido evitado, antes mesmo que ele tivesse se efetivado na forma de um ataque fatal à cachorra. Ocorre que Maria somente lembrou do sonho a posteriori, dando-se conta, então, de seu crucial significado. Segundo Júlio, a melhor maneira (e talvez única) de ter evitado o ocorrido, era ter atuado no próprio sonho. Para tanto, Maria deveria ter assumido a filiação de Sula, intervindo no assédio "do Onça", cuja forma onírica era Baixinho, o vereador baniwa. Esse sonho nos interessa aqui porque revela uma questão ambígua sobre a filiação adotiva. A moça ao lado de Maria era a sua cachorra Sula, mas quando Baixinho perguntou se podia levá-la, abrindo uma negociação matrimonial, Maria não reconheceu a filiação, revelando a origem de Sula, trazendo à tona a maternidade primeira de sua cachorra de estimação. Se Maria tivesse assumido Sula como sua filha no sonho, contou-me Júlio, a cachorra ainda estaria viva entre eles.

Há uma relação ambígua com os filhos adotados, o que vale tanto para a adoção de um antropólogo branco como para Sula, a cachorrinha de estimação, do mesmo modo que para os filhos maapatsi$k a$ (bastardos). Ambiguidade que se revela por meio do fato de que, diante de um dilema ou conflito, a origem do filho adotado, provisoriamente eclipsada, pode ser trazida à tona, desmascarada. Um evento pode facilmente desdobrar um reposicionamento. A contradição exposta por um filho branco que, no caso baniwa, pode ser notado na própria ambiguidade de um filho adotado (humano ou não humano), não inviabiliza o parentesco e a adoção, como tampouco desfaz a oposição índios e brancos.

\section{Modos de ser filho}

Há também outros modos possíveis dos meus anfitriões baniwa me classificarem e para tanto podemos recorrer às experiências de Júlio com os patrões não indígenas. Segundo explicou-me, enquanto conversávamos sobre os anos em que viveu e trabalhou na Venezuela e Colômbia, os patrões podem ser referidos em baniwa de três diferentes formas: -ialanawitte (branco/patrão), apidzawali (chefe) e iminali (dono). Para exemplificar, utilizou a nossa própria relação, dizendo para mim, "Nhoa piialanawitte", "Nhoa piapidzawali", "Nhoa piiminali", cujas traduções são, "Eu sou seu branco", literalmente, que pode ser entendido como "Eu sou seu patrão", "Eu sou seu chefe", "Eu sou seu dono". Eu percebi nesta conversa algo que já intuía: Júlio era não somente "tipo" meu pai, mas também “tipo" meu patrão. Em certo sentido, essa é a dupla face da paternidade, adotiva ou não.

O trabalho revela-se um modo de enunciar a relação de filiação. Lembremos da cena que descrevi em cima do caibro do telhado da cozinha de Maria em que Júlio me pede para não trabalhar, pois se assim fizesse ele pensaria que eu seria como seu filho. O "trabalhar juntos" é, no caso baniwa, ou então, para o caso da família de Júlio, um modo próprio de reconhecer vínculos de consanguinidade construída, análogo ao "comer juntos", já fartamente demonstrado na literatura etnológica das terras baixas da América do Sul (Overing 1983-1984; Gow 1991; Vilaça 1992; McCallum 2001; Costa 2013). Não 
somente a relação entre patrões e empregados é análoga à relação pais e filhos como o contrário, a relação de pais e filhos é análoga à relação entre patrões e empregados.

Retomando a conversa com Júlio, explicou-me que ele era o meu patrão/dono/chefe, porque eu estava na casa dele sob os seus cuidados e não o contrário. Esta era a perspectiva de Júlio sobre nossa relação, mas podemos considerar a perspectiva de um dos filhos de Júlio. Em determinada situação, o flagrei sendo inquirido na cidade por um parente baniwa sobre quem eu era, que estranhou ver Júlio acompanhado de um branco em seu barco. Antônio respondeu que eu era um maapatsika (bastardo) do pai dele. Assim, se eu era como um filho (ou empregado) para Júlio, do ponto de vista desse seu filho. Eu podia mesmo ser como um filho, mas do tipo bastardo.

A instabilidade na qual se situa a filiação adotiva, que pode ser experimentada em algum grau por qualquer filiação, pode ser expressa por meio da oscilação entre a aceitação e a negação de pais em relação aos filhos, bem como dos filhos em relação aos pais. Além do mais, há também torções do que seja um filho que podem variar entre um filho, um bastardo (maapatsika) e um empregado. No caso específico, a negação do filho adotado que é estrangeiro faz ele deslizar de uma posição de consanguíneo à posição de afim potencial (inimigo ou estrangeiro), um não parente, tal como eu me senti com Júlio quando onças, cobras e fofocas rondaram a mim e à casa de Júlio. Este é também o caso dos filhos suspeitos de não serem de quem a mãe aponta como pai, o caso dos filhos maapatsika. Nota-se, portanto, a ambiguidade que em especial envolve a filiação adotiva, mas não somente ela.

\section{Parentesco analógico}

Proponho um parentesco em obviação por meio da abordagem analógica de Wagner (1977) para notar a relação de filiação adotiva entre empregados baniwa e patrões brancos como um processo de consanguinização que eclipsa provisoriamente a parte-afim do patrão-branco, para que este possa ser considerado um "pai”. Isso somente é possível porque este procedimento desdobra o eclipsamento das relações do parentesco indígena, ou seja, o pai indígena é obviado para que o patrão se apresente como um parente análogo ao pai. Essa dinâmica figura-fundo nos auxilia a entender também as relações entre anfitriões indígenas e seus hóspedes antropólogos.

Patrão tem frequentemente o sentido de alguém tipo um pai, no entanto, seu vocativo é um termo distinto do vocativo baniwa $p a i^{15}$. Esse é um ponto importante, pois suspeito que não podemos nos desfazer da questão que nos coloca esta analogia, "tipo um pai" ou "como um pai". Para tanto, vejamos a definição de parentesco analógico para Wagner (1977):

A mother is another kind of a father, fathering is another kind of mothering; a sister might be a better sister for the fact that she is "a little mother" to her siblings, and a good father is often "like a brother" to his sons. A certain solicitude (perhaps epitomized by Schneider's "enduring, diffuse solidarity") is quintessential to all ideal kin relationships, regardless of how they may be defined or in what forms the solicitude is expressed. And this solicitude represents, as well as anything can

$15 \mathrm{O}$ termo de referência para pai, em baniwa, é noniri, “meu pai”. 
represent, what I mean by the basic analogy of all kin relationships to one another. [...] All kin relationships and "kinds" of kinsmen are basically analogous because all incorporate the essence of human solicitude that we call "relating." Every particular "kind" of relationship exemplifies this essence in some particular way, and comprises a ("metonymic") part of a potential whole, a totality of which the aggregate of all the kinds of relationship represents a homologue. Each particular kind of relationship, since it incorporates the underlying context of relational solicitude, can be seen as an ("metaphorical") analogue of each other kind of relationship (Wagner 1977: 623-624).

Para Wagner, metáfora é uma analogia. No que toca o nosso problema, isso significa apontar que o patrão como um pai não é o mesmo que dizer que ele é um pai falso, ou uma metáfora no seu sentido figurativo. Proceder assim é desqualificar a própria analogia enquanto relação. Poder-se-ia objetar que o patrão é como um pai, mas não é pai tal como 'o’ pai "real". Compartilho desta observação desde que concordemos que 'o' pai “real” é também ele um tipo de pai, um tipo de parente, pois ele é também, como disse Wagner (1977), um tipo de mãe que é um tipo de pai que é um tipo de irmão mais velho que é um tipo de irmão mais novo que é um tipo de primo que é um tipo de amigo e assim por diante. Os relacionamentos são todos análogos entre si, versões diferentes da solicitude generalizada implicada em toda relação de parentesco. $\mathrm{O}$ antropólogo que vive em uma comunidade indígena não está "fora" deste campo analógico. Assim, podemos problematizar a relação de filiação adotiva. Sobre isso, Fausto observa:

Há um último ponto que gostaria de marcar: a adoção é, por assim dizer, uma filiação incompleta. Ela não produz uma identidade plena, senão uma relação ambivalente, em que o substrato da inimizade é obviado, mas não inteiramente neutralizado. Daí a minha insistência na permanência da perspectiva do outro no caso da relação xamã-auxiliares ou matador-vítima; daí também por que cativos de guerra e animais familiares frequentemente recebem um tratamento oscilante entre o cuidado e a crueldade. À dupla-face do mestre corresponde a face-dupla do xerimbabo: ele é um outro e jamais deixará de sê-lo completamente (Fausto 2008: 352).

Notemos que para que a adoção possa ser entendida como uma filiação incompleta, precisa-se pressupor a filiação "legítima" como completa, a saber, de identidade, o que está em desacordo com a abordagem wagneriana que sigo aqui. A oposição entre filiação (legítima) e filiação adotiva não é absolutamente pertinente no contexto baniwa e, neste caso, não devemos pressupor a filiação "legítima" como sendo marcada por uma relação que não contém em si diferença. Compreende-se aqui que uma certa perspectiva do outro permanece mesmo que somente potencialmente nas relações dado as suas características analógicas. Para Fausto, tudo se passa como se um pai não pudesse assumir também para o seu filho "legítimo" uma dupla face, ou o contrário, um filho não pudesse assumir para o pai "real" uma dupla face. Mesmo entre os Baniwa, comunidade caracterizada por um ambiente patrilinear, é possível notar que, por exemplo, entre um pai e seu filho mais velho pode, principalmente depois que este último está casado e têm filhos e às vezes netos, projetar-se uma rivalidade e insinuar-se uma diferença entre eles. Na medida em que eles se equiparam frente à comunidade, é como se eles se afinizassem em algum grau, pai e filho mais velho seriam igualmente donos-mestres. Ademais, no caso baniwa, os filhos mais velhos podem se lembrar de circunstâncias em que o pai não foi tão cuidadoso e protetor 
como eles julgavam que ele deveria ser, acusando o pai de ter se comportado como um afim. Este é o motivo análogo pelo qual um patrão se torna um inimigo, ou seja, não se comporta como um pai deve se comportar.

Estas diferenças notadas na filiação não são uma exclusividade baniwa. Soares-Pinto (2015) descreveu para os Djeoromitxi que certa rivalidade entre pais e filhos mais velhos se delineia como a própria maneira de produzir uma territorialização do grupo, pois na medida em que essa diferença se insinua, o filho mais velho abre uma nova aldeia. Calávia Sáez (2006:182), para os Yaminawa, aponta que "O padrinho-patrão é um "parente" externo e construído, mas também um doador, de bens e de nome, como o pai":

A sovinice do patrão não o separa necessariamente do pai. As relações entre pais e filhos estão não raro marcadas pela cobiça dos bens dos velhos: se a concessão de aposentadorias da Funrral aos velhos pode ter acirrado recentemente essa cobiça, ela se estende também a itens tradicionais: lembro bem o prazer furtivo com que um jovem Yaminawa se apossava dos arcos e tarrafas de seu pai durante as ausências deste (idem: 183).

Conforme aponta o autor, nem mesmo a sovinice alegada do patrão enfraquece a analogia deste com os pais yaminawa. A construção apontada por Calávia Sáez é revelada por meio de uma analogia. Isso corrobora com a proposta de Wagner (1977) de que todo o parentesco é analógico e com a proposta de Viveiros de Castro (2002c) de que todo o parentesco é construído porque resultado de uma ação deliberada de extrair consanguinidade da afinidade. Dito isso, relações analógicas e construídas não significam relações falsas ou fictícias, como tampouco a própria filiação "legítima” é plena e pura. Em certo sentido, toda a filiação é adotiva, porque toda relação é construída, mesmo aquela que em determinadas situações se apresenta como sendo dada. O pai adotivo é um tipo de pai legítimo, mas também o inverso é verdadeiro. O patrão funciona, assim, como um termo cuja extensão possibilita vermos a complexidade "analógica" dessas posições no campo do parentesco.

\section{Desconhecendo e reconhecendo}

Júlio contou uma história sobre seu tio Amácio, um finado pajé baniwa do clã Hohodene, a respeito do longo período em que ele ficou sozinho com sua esposa no sítio Cará-igarapé, localizado num afluente homônimo do rio Aiari. Ele contou que, certo dia, uma missionária católica chegou ao seu sítio, perguntando por que ele vivia sozinho com a sua esposa. Ele então respondeu que era porque seus filhos tinham ido embora trabalhar em algum lugar no Brasil, Venezuela ou Colômbia, junto aos patrões do sistema extrativista. Ela então prometeu que acionaria o governo e que eles voltariam. Amácio não acreditou, mas para sua surpresa, um tempo depois, quando ele e sua esposa estavam na roça, ouviram um grande barulho - era um helicóptero. O finado pajé se aproximou cautelosamente de sua casa, pois era lá que havia pousado. De longe pôde ouvir uma música alta de rádio, risadas e conversas; ao se acercar, notou a presença de homens e mulheres brancas com chapéu de diferentes tipos, todos usando calça comprida, cinturões com terçado ou revólver, grandes botas, tudo à moda dos patrões co- 
lombianos. Todos falavam línguas estrangeiras, algumas destas Amácio reconhecia, como o espanhol e o português, mas uma das mulheres falava uma língua desconhecida que Júlio suspeita ser inglês, pois ela diria depois que viera da América.

Uma dessas pessoas descobre o velho em espreita e pergunta-lhe quem ele era, mas ele devolve a pergunta: - “Puxa vida, quem são vocês, o que vocês estão fazendo? O que vocês vieram buscar?”. Em espanhol, um dos homens respondeu que eles eram daquele lugar, nascidos naquele sítio e que voltaram apenas porque haviam recebido a mensagem do governo de que o pai deles os chamava de volta. Até então desconhecidos um para os outros, reconhecem-se mutuamente em clima de regozijo. Com medo, a esposa de Amácio havia ficado na roça, aguardando notícias, e ele ao buscá-la anunciou: "Eles são nossos filhos que voltaram, eles voltaram todos, tem Alberto, Laureano, Maria e Antônia, são nossos filhos, mas eles são brancos já, ninguém reconhece mais eles". Ela então respondeu: - "Ah... Nossos filhos? O que será que nossos filhos vão fazer a mim?”. Demovendo-a do receio que sentia, Amácio respondeu: - “Não, não faz nada, nossos filhos. Bora lá!”. Segundo Amácio, eles demoraram a falar baniwa novamente e mesmo assim ainda falam de forma "feia".

Essa digressão mítico-histórica ilumina o fato de que as suspeitas que recaíram sobre mim e as queixas sobre a provisoriedade que eu impunha à relação com o meu casal anfitrião não me eram exclusivas, uma vez que, como vimos na história de Amácio, podem ser atualizadas também por filhos "legítimos". Lembremos que Maria em seu cântico dramatizava poeticamente suas desconfianças, a saber, se eu "voltaria", se "agradeceria" adequadamente e se seria capaz de reconhecer o tratamento que ela me conferia. Essa suspeição marca também a relação com os "filhos legítimos", como no caso dos filhos de Amácio que saíram da casa dos pais sem dar notícias por longos anos, voltando apenas devido a uma ordem do governo. Essa história de separação é a de muitos pais baniwa que "perderam" temporária ou definitivamente os seus filhos para os patrões a partir dos ciclos da indústria extrativista no Alto Rio Negro, pelo menos desde meados do século XIX, para as guerrilhas na fronteira com a Colômbia na década de 1980, e mais recentemente, para as cidades. Acima, delineei principalmente a analogia entre pai e patrão para apontar a suspeição que os filhos podem guardar em relação aos seus pais, mas aqui temos também acesso às desconfianças que os pais podem experimentar em relação aos filhos.

Com estes dois exemplos etnográficos em consideração, podemos compreender que ser branco é, entre outras coisas, um índice de suspeição (dir-se-ia também uma fronteira) situado na teia relacional baniwa. Ocorre que de modo análogo ao fato de que um "filho branco" é suspeito, por sua origem, um filho indígena legítimo, contingencialmente porque distante e, portanto, por seu destino, se torna suspeito e isso pode ser expresso notando justamente que ele se tornou branco. Lembremos como o Amácio anunciou o retorno dos seus filhos, “[...] são nossos filhos que voltaram [...], mas eles são brancos já, ninguém reconhece mais eles”, para desconfiança da mãe que temeu o eles poderiam fazer a ela. Nesses casos, o "ser branco" nada tem de essencial ou substancial, o que nos permite entender que não somente um branco pode se tornar filho, como um filho pode se tornar branco. Notamos nessas variações, no que concerne à filiação, que se reconhece uma sempre possível insinuação de diferença nas relações. 
Sobre isso, Taylor (2001) aponta que entre os Jivaro é a introdução realizada pela afinidade, do componente de alteridade interna a cada termo da relação, o que torna as relações propriamente sociais entre parentes consanguíneos de mesmo sexo, dado que "even same-sex children (in relation to ego) are never fully and truly consanguineal' (idem:51). Nesses termos é que podemos entender, como a autora, que relação é diferença. Ademais, a partir do Wagner (1977; 2010), podemos assinalar que a dinâmica relacional é marcada pela reversibilidade, mesmo, por exemplo, na filiação "legítima”. Assim, do mesmo modo que as relaçóes baniwa guardam potencialmente analogias com outras, sempre há nelas uma perspectiva de Outro.

\section{Conclusão}

O título deste artigo é uma paráfrase do subtítulo do livro Staying with the Trouble: making kin in the Chthuluceno de Haraway (2016a). Isso porque, o meu propósito, como o desta autora, era fazer com que "parente" significasse algo diferente do que na nossa tradição ocidental moderna, delineando uma socialidade que recusa um viés essencialista que podemos localizar nas ideias euro-americanas hegemônicas de consanguinidade. Haraway propõe isso a partir de "parentescos-inovadores não natais com indivíduos e coletivos em mundos queer, descoloniais e indígenas" (2016b: 145), discutindo processos imigratórios e criticando as campanhas de pró-natalidade na Europa. As inovações no parentesco (kinnovation) se apresentam como um dos caminhos que Haraway encontra para propor recomposições no Antropoceno, nova época geológica marcada pelo esgotamento ambiental-político-social-cultural-subjetivo e cujas causas são antrópicas. Nesse sentido, a autora diz que é preciso seguir "pistas e estímulos para sismos na criação de parentes não limitados aos dispositivos da família ocidental, heteronormativos ou não" (idem: 144). Os tensionamentos do parentesco que a filósofa feminista propõe se alinham àquilo que os Baniwa e os povos indígenas de maneira geral sempre fizeram. Isto é, o reconhecimento da fabricação como modus operandi dos processos de parentesco - haja vista a literatura etnológica (Seeger; DaMatta; Viveiros de Castro, 1987; Coelho de Souza 2001; Overing 19831984; Viveiros de Castro 2002). O que sugere que os povos indígenas parecem ter muito a ensinar aos não indígenas sobre parentesco.

Nesse trabalho em específico, pretendi demonstrar como esta crítica ao parentesco euroamericano hegemônico é realizada pelos Baniwa, demonstrando que os seus modos de constituir parentes têm como pressuposto uma relacionalidade generalizada que não estipula a priori os seus limites, revelando uma "abertura ao Outro" (Lévi-Strauss 1993). Assim, o que pretendi experimentar aqui por meio da minha relação com os Baniwa é uma descrição que aponta para um tipo de abertura do parentesco de que fala Haraway.

O parentesco analógico de Wagner (1977) se mostrou uma abordagem interessante para fazer notar essa abertura e a extensão dos limites do campo de parentesco e, assim, expressões "como se" ou "tipo" podem apontar para relações como não sendo falsas ou fictícias. A propósito do pacto etnográfico (Albert 2015), ressalto que mesmo que os antropólogos sejam entendidos como emissários de um 
mundo nefasto, quando não indígenas e assim potencialmente inimigos ${ }^{16}$, isso não implica a impossibilidade de uma formulação via parentesco destas relações interétnicas. Não há de antemão uma impossibilidade formal de inimigos se tornarem parentes, como tampouco de parentes se tornarem inimigos. Nesse sentido, o parentesco baniwa, e o ameríndio de maneira geral, confronta-nos e expõe-nos - antropólogos não indígenas, sociedade ocidental moderna - de diferentes maneiras. Porém, nada aqui deve sugerir que os Baniwa compreendam os seus parentes como um conjunto de relações harmônicas em uma sociabilidade marcada pela identidade plena. Uma comunidade de parentes é também uma comunidade de diferenças, mesmo em seus vínculos mínimos ${ }^{17}$, por isso mesmo, o parentesco baniwa, e vimos aqui apenas alguns de seus vislumbres, é uma construção perpétua e complexa que envolve experimentações, apostas, afirmações e reversões. Para os Baniwa, ao contrário do que se concebe sob a ideia de uma hereditariedade genética, o parentesco não está inscrito à revelia das ações em algum código ou instância fixa e por isso precisa ser meticulosa e continuamente estabelecido.

O parentesco é exigente e, assim entendido, tem consequências importantes para a relação que um antropólogo estabelece em trabalho de campo com seus anfitriões indígenas. $\mathrm{O}$ antropólogo, mesmo que não reconheça relações de parentesco durante o trabalho de campo com os seus anfitriões e interlocutores, precisa estar atento ao que o parentesco indígena demanda. Assim, ao mesmo tempo em que ele precisa obviar constantemente a sua parte-afim-inimiga, deve produzir relações não por identidade, mas pela diferença que encarna. Afinal, como apontou Viveiros de Castro (2002), o processo de parentesco é para os povos ameríndios em geral uma ação deliberada de extrair consanguinidade da afinidade. Trata-se de uma costura constante e criativa, e se isso é mais evidente a partir da relação entre este antropólogo e os seus anfitriões, isso não significa que também não o seja para os Baniwa entre eles. O modo como o antropólogo é pressionado a fazer parentesco em trabalho de campo em uma comunidade indígena pode transformá-lo em um parente e, mesmo que isso não ocorra, transforma ao menos provisoriamente o modo como ele produz suas relações durante a pesquisa etnográfica entre os seus interlocutores e anfitriões.

\section{João Jackson Bezerra Vianna é professor da Universidade Federal do Espirito Santo (UFES), doutor em Antropologia Social pela Universidade Federal de Santa Catarina (UFSC), mestre em Antropologia Social pela Universidade Federal do Amazonas (UFAM) e psicólogo pela Universidade Federal de Rondônia (UNIR).}

16 Seria interessante compreender a posição que ocupa os antropólogos indígenas que pesquisam seu próprio povo. 17 Se apontei aqui diferenças se insinuando nas relações de filiação, Andrello (2019) descreve diferenças se insinuando nas relações de germanidade entre os Tukano. 


\section{REFERÊNCIAS BIBLIOGRÁFICAS}

ALBERT, Bruce. 2014. "Situação Etnográfica” e Movimentos Étnicos. Notas sobre o trabalho de campo pós-malinowskiano. Campos 15(1):129-144.

2015. Postscriptum - Quando eu é um outro (e vice-versa). In.: KOPENAWA, Davi

\& ALBERT, Bruce. A queda do céu: palavras de um xamã yanomami. São Paulo: Companhia das Letras.

ANDRELLO, Geraldo. 2019. De irmãos e cunhados. Formas da diferença no rio Uaupés. In.: SÁEZ, Oscar Calavia (Org.). Ensayos de teoría etnográfica en las tierras bajas de América del Sur. Madrid, Nola Editores.

ANDRELLO, Geraldo. 2006. Cidade do Índio. Transformações e cotidiano em Iauareté. São Paulo: Editora UNESP: ISA; Rio de Janeiro: NUTI.

BONILLA, Oiara. 2005. O bom patrão e o inimigo voraz: predação e comércio na cosmologia Paumari. Mana, 11(1):41-66.

COELHO DE SOUZA, M. 2001. Nós, os vivos: "construção da pessoa" e "construção do parentesco" entre alguns grupos jê. Revista Brasileira de Ciências Sociais, São Paulo, v. 16, n. 46, p. 69-96.

COUTINHO, Gabriel. 2007. Os Aparai e Waiana e suas redes de intercâmbio. Tese: São Paulo: PPGAS/USP.

COSTA, Luiz. 2016. Virando funai: uma transformação Kanamari. Mana 22(1): 101-132.

FAUSTO, Carlos. 2008. Donos demais: Maestria e domínio na Amazônia. Mana. Estudos de Antropologia Social, 14(2):329-366.

FIRTH, Raymond. 1998. Nós, os Tikopias. Um estudo sociológico do parentesco na Polinésia primitiva. Edusp, São Paulo.

GOW, Peter. 1991. Ofmixed blood: kinship and history in Peruvian Amazonia. Oxford: Clarendon Press. HARAWAY, Donna. 2016a Staying with the trouble: making kin in the Chthuluceno. Duke University Press.

.2016b. Antropoceno, Capitaloceno, Plantationoceno, Chthuluceno: fazendo parentes. ClimaCom Cultura Cientifica - pesquisa, jornalismo e arte, I Ano 3 - N. 5.

HUGH-JONES, Stephen. 1992. “Yesterday's luxuries, tomorrow's necessities: business and barter in northwest Amazonia" In S. Hugh-Jones \& C. Humphrey (eds), Barter, Exchange and Value. An anthropological approach. Cambridge: Cambridge University Press.

JOURNET, Nicholas. 1995. Les paix des jardins: Structures sociales des Indiens curripaco du haut Rio Negro (Colombie). Paris: Institut D’Ethnologie, Musée de L'Homme.

KELLY, José. 2005. Notas para uma teoria do “virar branco". Mana 11(1):201-234.

KILLICK, Evan. 2008. Godparents and Trading Partners: Social and Economic Relations in Peruvian Amazonia. Journal of Latin American Studies.

KOCH-GRÜNBERG, Theodor. 2005. Dois anos entre os indigenas. Manaus, EDUA, FSDB.

LÉVI-STRAUSS, C. 1993. História de Lince. São Paulo: Companhia das letras.

MCCALLUM, Cecilia 2001. Gender and sociality in Amazonia: how real people are made. Oxford: Berg. 
MATOS, M. A. 2018. Organização e história dos Manxineru do alto rio Iaco. Tese: Santa Catarina: PPGAS/UFSC.

MELATTI, J. C. 1976. Nominadores e genitores: um aspecto do dualismo krahô. In: SCHADEN, E. (Org.). Leituras de etnologia brasileira. São Paulo: Companhia Editorial Nacional, pp. 139-149. OVERING, Joanna. 1983-1984. Elementary structures of reciprocity: a comparative note on Guianese, Central Brazilian, and North-West Amazon sociopolitical thought. Antropológica, n. 59-62, p. 331-348.

RAMOS, Alcida Rita, Silverwood-Cope, Peter e OLIVEIRA, Ana Gita. 1980. Patrões e clientes: relações intertribais no Alto Rio Negro. In: Hierarquia e simbiose: relações intertribais no Brasil. São Paulo: HUCITEC. pp. 135-182.

SÁEZ, Oscar. 2006. O nome e o tempo dos Yaminawa: etnologia e história dos Yaminawa do rio Acre. São Paulo/ Rio de Janeiro, Editora da Unesp, ISA e NUTI.

SANTOS-GRANERO, F. 2007 Of fear and friendship: Amazonian sociality beyond kinship and affinity. Journal of the Royal Anthropological Institute, London, v. 13, n. 1, p. 1-18.

SOARES-PINTO, Nicole. 2018. Uma incontornável diferença: parentesco nas Terras Baixas da América do Sul (1996-2016). BIB, São Paulo, n. 87, 3, pp. 105-132. 2014. Entre as teias do marico: parentes e pajés djeoromitxi. 2014. 492 f. Tese: Brasília: UNB.

SEEGER, A. 1981. Nature and society in central brazil: the suya Indians of Mato Grosso. Cambridge: Harvard University Press.

SEEGER, A.; DA MATTA, R.; VIVEIROS DE CASTRO, E. B. 1987. A construção da pessoa nas sociedades indígenas brasileiras. In: OLIVEIRA, J. P. (Ed.). Sociedades indigenas e indigenismo no Brasil. Rio de Janeiro: Marco Zero, p. 11-29.

TAYLOR, Anne-Cristine. 2001. “Wives, Pets and Affines: Marriage among the Jivaro”. In: L. M. Rival and N. L. Whitehead (Org.). Beyond the visible and the material: the ameriandinization of society in the work of Peter Riviere. Oxford, Oxford University Press: pp. 45- 56.

VIVEIROS DE CASTRO, Eduardo. 2002 “O problema da afinidade na Amazônia”. In: A inconstância da alma selvagem. São Paulo, Cosac e Naify, pp. 87-180.

VIANNA, João. 2017 Kowai e os Nascidos: a mitopoese do parentesco baniwa. Tese: Florianópolis: PPGAS/UFSC.

WAGNER, R. 2010. A invenção da cultura. São Paulo, Cosac e Naify. . 1977. "Analogic Kinship: A Dabiri Example”. American Ethnologist, v.4, n.4, pp. 623-42. 1974. Are there social groups in the New Guinea Highlands? In: LEAF, M. (Ed.).

Frontiers of anthropology. New York: D. Van Nostrand Company, p. 95-122.

WALKER, H. 2013 Under a Watchful Eye: Self, Power and Intimacy in Amazonia. Berkley, Los Angeles, London: University of California Press.

WRIGHT, R. 2005 História Indígena e do Indigenismo no Alto Rio Negro. Campinas: Mercado de Letras. 


\section{FAZENDO PARENTES ENTRE OS BANIWA: REFLEXÕES SOBRE AS RELAÇÕES EM}

\section{CAMPO}

Resumo: Este artigo é uma investigação de algumas das relações possíveis entre antropólogos e seus anfitriões indígenas, considerando o parentesco como abordagem analítica pertinente. Para tanto, parto da minha experiência etnográfica entre os Baniwa, povo de língua arawak que vive no Noroeste Amazônico, descrevendo o vínculo que se estabeleceu entre mim e o casal Júlio e Maria, meus principais anfitriões. Procuro compreender como esta relação indicia diferentes posições dentro do campo do parentesco, sempre reversíveis, caracterizando modos dinâmicos de fazer parentes. Seguindo a ideia de um parentesco analógico (Wagner, 1977), demonstrarei como um antropólogo branco e seus anfitriões baniwa se situam em uma cadeia de analogias: brancos e indígenas, patrões e empregados, pais e filhos (adotivos, "bastardos" e "legítimos"). Ao final proponho alguns entendimentos sobre o parentesco baniwa a partir do modo como ele é constituído em uma das fronteiras do seu campo: na relação com os brancos.

Palavras-chave: Baniwa; Noroeste Amazônico; Trabalho de campo; Parentesco analógico.

\section{MAKING KIN RELATIONSHIPS AMONG THE BANIWA: REFLECTIONS ON THE FIELD RELATIONS}

Abstract: From my ethnographic research among the Baniwa - a people who live in the Northwest Amazon and whose language is Arawak - this article consists in an investigation into some possible relations between anthropologists and their indigenous hosts. In order to do that, I describe the bond established between me and the Baniwa couple, Júlio and Maria, who are my main hosts. This article uses kinship as its pertinent analytical approach. I aim in understanding how this relation gives evidence of different and always reversible positions in the field of kinship. These positions characterize dynamic modes of making kin. Drawing on the ideia of analogic kinship (Wagner, 1977), I will show how a white anthropologist and his Baniwa hosts are situated in the following analogies chain, white and indigenous people, bosses and workers, parents and adopted, bastard and legitimate children. At the end, I propose some understandings about Baniwa kinship from the way in which it is constituted in one of its field's boundaries: in the relationship with white people

Keywords: Baniwa; Northwest Amazon; Fieldwork; Analogic kinship.

RECEBIDO: $10 / 04 / 2019$

APROVADO: $20 / 05 / 2019$ 